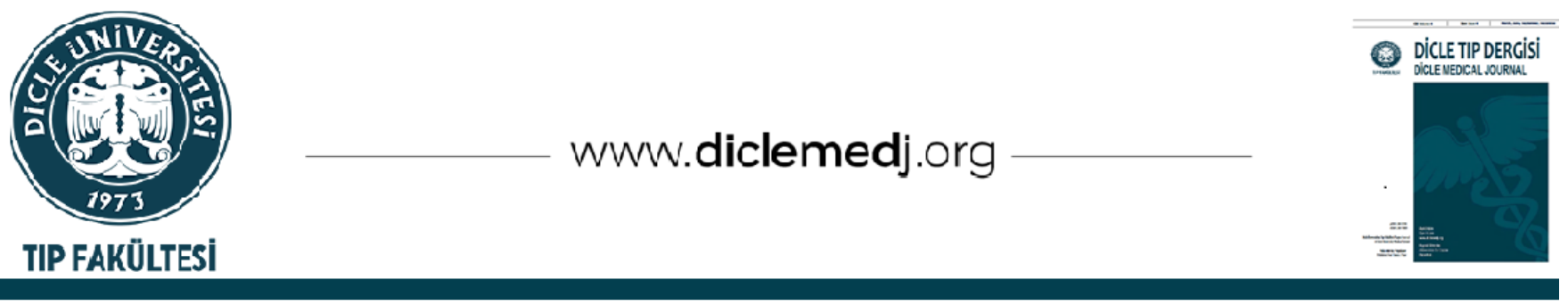

Özgün Araştırma / Original Article

\title{
Lumbal Disk Hernili Hastalarda Hastalık Evresi Postüral Kontrolü Etkiler Mi?
}

\author{
Melda Soysal Tomruk ${ }^{i}$, Alp Tunca Yapıcı ${ }^{\left(D_{2}\right.}$, Nihal Gelecek ${ }^{D_{3}}$, Orhan Kalemci ${ }_{4}$ \\ 1 Burdur Mehmet Akif Ersoy Üniversitesi Sağlık Bilimleri Fakültesi, Fizyoterapi ve Rehabilitasyon Bölümü, Burdur, Türkiye \\ 2 Dokuz Eylül Üniversitesi, Sağlık Bilimleri Enstitüsü, İzmir, Türkiye \\ 3 Dokuz Eylül Üniversitesi, Fizik Tedavi ve Rehabilitasyon Yüksekokulu, İmir, Türkiye \\ 4 Dokuz Eylül Üniversitesi, Tıp Fakültesi, Beyin ve Sinir Cerrahisi Anabilim Dalı, İzmir, Türkiye
}

Geliş: 25.01.2021; Revizyon: 23.05.2021; Kabul Tarihi: 24.05.2021

Öz

Amaç: Lumbal disk hernisi (LDH) genellikle L5-S1 düzeyinde meydana gelen, ağrı ve somatosensöriyel kayıplara neden olan bir durumdur. $\mathrm{Bu}$ nedenle hastalarda postüral kontrolde azalmalar meydana gelir. Çalışmanın amacı LDH hastalarında hastalık evresinin postüral kontrole etkisini araştırmaktı.

Yöntemler: Çalışma kesitsel bir araştırmadır. Çalışmaya bulging evresinde 22, protrüzyon evresinde ise 33 hasta olmak üzere L5-S1 seviyesinde LDH olan 55 hasta dahil edildi. Hastaların ağrı, özürlülük ve postüral kontrolleri sırasıyla; Görsel Ağrı Skala (GAS), Oswestry Özürlülük İndeksi ve Biodex denge cihazı ile ölçüldü. Postüral kontrol değerlendirmesi için kararlılık sınırları (KS) ve duyusal etkileşim denge testi (DEDT) kullanıldı. Gruplar arası farklar, Student's t test testi ile belirlendi.

Bulgular: Gruplar arasında yaş, hastalık süresi, ağrı ve özürlülük düzeyi açısından anlamlı fark yoktu (p>0.05). Bulgingi olan grubun sol yön KS test skoru protrüzyon evresinde olan hastalardan anlamlı ölçüde düşüktü ( $<<0.05)$. Yumuşak zemin DEDT skorları bulgingi olan grupta, protrüzyon olan gruba göre anlamlı ölçüde yüksekti $(\mathrm{p}<0.05)$.

Sonuç: L5-S1 seviyesinde protrüzyonu olan hastaların, bulgingi olan hastalara göre yumuşak zemindeki duyusal etkileşim dengelerinin daha iyi olduğu görüldü. Her iki grupta sol yön dışında kararlılık sınırları benzerdi. Bu bulgular ışığında çalışmamız, farklı hastalık evresine sahip L5-S1 düzeyinde tutulumu olan LDH hastalarında postüral kontrolün vestibuler ve proprioseptif girdinin değişmesiyle etkilenebileceğini gösterdi. Bu nedenle bu hastaların tedavisinde hastalık evrelerine göre postüral kontrolün geliştirilmesine yönelik yaklaşımların uygulanması önerilir.

Anahtar kelimeler: Denge, postüral kontrol, lumbal disk hernisi, bel ağrısı

DOI: 10.5798/dicletip.944401

Yazışma Adresi / Correspondence: Melda Soysal Tomruk, Burdur Mehmet Akif Ersoy Üniversitesi Sağlık Bilimleri Fakültesi, Fizyoterapi ve Rehabilitasyon Bölümü, Burdur, Türkiye Posta Kodu: 15030 e-mail: meldasoysaltomruk@gmail.com 


\title{
Does Disease Stage Affect Postural Control In Patients With Lumbar Disc Herniation?
}

\begin{abstract}
Objective: Lumbar disc herniation (LDH) is a condition that usually occurs at the L5-S1 level, causing pain and somatosensory loss. Therefore, decreases in postural control in patients come to the fore. The aim of the study was to investigate the effect of disease stage on postural control in patients with LDH.

Methods: The study was a cross-sectional study. Fifty-five patients with LDH at the L5-S1 level, 22 of them in the bulging phase and 33 in the protrusion phase, were included in the study. Pain, disability and postural control of the patients were measured with Visual Pain Scale (VAS), Oswestry Disability Index and Biodex balance device; respectively. Limits of stability (LOS) and sensory interaction balance test (SIBT) were used for postural control evaluation. Between groups differences were determined by Student's t test.

Results: There was no significant difference between groups in terms of age, disease duration, pain and disability level ( $p>0.05$ ). Left-side LOS test score of bulging group was significantly lower than the patients' with protrusion stage $(p<0.05)$. Foam surface SIBT scores of bulging group were significantly higher than protrusion group $(\mathrm{p}<0.05)$.

Conclusion: It was observed that patients with protrusion at the L5-S1 level had better sensory interaction balance on foam surfaces compared to patients with bulging. Limits of stability were similar in both groups except for the left direction. In light of these findings, our study showed that postural control of LDH patients with L5-S1 involvement with different disease stages, can be affected by alteration of vestibular and proprioceptive input. For that reason, it is recommended to apply approaches to improve postural control according to the disease stages in the treatment of these patients.
\end{abstract}

Keywords: Balance, postural control, lumbar disc herniation, low back pain.

\section{GíRiş}

Postüral kontrol, merkezi sinir sisteminin kontrollü bir duruşu sürdürmek için farklı sistemlerden gelen duyusal bilgileri düzenleyen mekanizmayı tanımlamak için kullanılan bir terimdir. Postüral kontrol, yerçekimine, destek yüzeyine, eksternal ve internal girdilere göre vücudun duruş ve hareketlerini kontrol eden bir mekanizmadır. Görsel, vestibüler ve somatosensör sistemler postüral kontrol ve denge ile ilgili temel duyu sistemleridir. Bu uyaranların işlenmesi ile ağırlı merkezi kararlılık sinırları içinde tutulabilir ve stabilizasyon için gereken duyu-motor stratejilerinin koordinasyonu gerçekleşmiş olur. Etkin bir postüral kontrol, kompansatuvar hareketler açığa çıkmadan, konum ve hareketteki değişikliklere yanıt olarak küçük ayarlamalar yapma yeteneğini gerektirir ve böylece kişi kontrollü bir orta hat postürü içinde, gerekli olan kassal aktivasyonu kullanarak çeşitli statik ve dinamik aktivitelerde bulunabilir. Bu nedenle, postüral kontrolün çok yönlü olarak kararlılık sınırları, postüral stabilite ve duyusal denge açısından ele alınması önemlidir ${ }^{1,2}$.

Kişide postüral kontrol mekanizmasını bozan muskuloskeletal hastalıkların başında kronik bel ağrıları gelmektedir. Kronik non-spesifik bel ağrılarında hissedilen ağrı nedeniyle somatosensöriyel girdinin azalması, hareket korkusu (kinezyofobi) ve alternatif hareket stratejilerinin ortaya çıkması postüral kontrolü azaltan ana faktörlerden bazılarıdır ${ }^{3-5}$. Ağrının şiddetine bağlı olarak, afferent nöronlarda meydana gelen artmış pre-sinaptik inhibisyon veya kaslardan alınan proprioseptif girdilerin modülasyonunun etkilenmesi, postüral salınımlarda artışa yol açar. Bu artış, kararlılık sınırlarının aşılmasına ve duyusal sistemin girdilerine yanıt olarak elde edilen dinamik postüral kontrolün sağlanmasında güçlüklere neden olur ${ }^{6-9}$. 
Lumbal disk hernisi (LDH), en sik L5-S1 düzeyinde görülen ve lumbopelvik stabiliteyi bozan bir durum olarak karșımıza çıkmaktadır. Lumbal disk hernilerinde diğer patolojilerden farklı olarak; çeşitli alt ekstremite ve gövde kaslarında, sinir kökündeki basının şiddetine ve etkilenen sinir köküne göre değișmekle birlikte kas kuvvetinde ve tendon reflekslerinde azalma olabilir. Lumbal disk hernisinde görülen bel ağrıları veya sinir kökü basısına bağlı olarak kaslarda oluşan imbalans nedeniyle ağırlık aktarma yeteneğinde gerileme ve ayaklarda basınç asimetrisi görülmektedir. Bu durumla birlikte gelișen propriosepsiyondaki azalma postüral kontrolü olumsuz yönde etkiler. Bunun yanında alt ekstremitelerde meydana gelen ağrı ve proprioseptif kayı, hareket koordinasyonunun bozulmasına ve kronik sağlık sorunu oluşturarak yaşam kalitesinin azalmasına neden olur. Sonuç olarak hastalarda postüral kontrol kayıpları meydana gelir 10-16.

Yapılan çalışmalarda kronik bel ağrısında ve LDH nedeniyle cerrahi geçiren hastalarda dinamik postüral kontrolün genellikle postüral stabilite ve kararlılık sinırları test edilerek değerlendirildiği gözlenmiştir. Fakat bu muskuloskeletal rahatsızlıklardan farklı olarak cerrahi endikasyonu olmayan LDH'lı hastalarda günlük yaşam aktivitelerinde daha fazla özürlülük ve fonksiyon kaybına neden olan hastalı evresinin, postüral kontrole olan etkisi ayrıntılı olarak değerlendirilmemiștir. $\mathrm{Bu}$ hastalarda hastalık evresinin göz önüne alınarak postüral kontrolün kararlılık sınırları ve duyusal etkileşim açısından değerlendirilmesi, hastalık nedeniyle bozulan somatosensöriyel ve olası vestibuler kayıpların belirlenebilmesi açısından yol gösterici olacaktır.

Bu bağlamda çalışmanın amacı; lumbal bölgede sık görülen L5-S1 düzeyinde LDH olan hastalarda bulging ve protrüzyon evrelerinin postüral kontrole etkisinin saptanmasıdır. Çalışmanın hipotezi ise, bulgingli hastalarda postüral kontrol, protrüzyonlu hastalara göre daha iyidir șeklindedir.

\section{YÖNTEMLER}

\section{Dizayn}

Çalışma kesitsel bir araştırma olup, Haziran 2017 ve Mayıs 2018 tarihleri arasinda yapılmıştır.

\section{Katılımcılar}

Çalışmaya, 18 yaş üstü, çalışmaya katılmaya gönüllü, lumbal disk problemleri şikayeti ile Beyin ve Sinir Cerrahi polikliniğe başvuran, seviyesi ve evresi MRI ile tanımlı ve tanı süresi en az 6 ay olan 55 hasta alınd. Alt ekstremiteleri etkileyen nörolojik veya kas-iskelet sistemi hastalığına sahip olan, postüral kontrolü etkilemesi muhtemel olan görme problemlerine sahip olan, amputasyon veya yardımc cihaz kullanan, hamile olan, disk problemlerine ek ciddi sistemik hastalığı bulunan (tümör, enfeksiyon, osteoporoz, diyabetes mellitus, $\mathrm{M}$. Becterew gibi romatolojik hastalıklar), kooperasyonu engelleyecek düzeyde mental ve kognitif bozuklukları olan ve çoklu seviyede disk problemlerine sahip olan hastalar ise çalışma dışı bırakıldı.

Çalışma için Üniversitenin Girişimsel Olmayan Klinik Araştırmalar Etik Kurulu'ndan 08.06.2017 tarih ve 2017/15-20 karar numarası ile izin alındı. Katılımcılara Helsinki Deklerasyonu baz alınarak yazılı aydınlatılmış onam formu okunup imzaları alındı.

\section{Prosedür}

Çalışmaya dahil edilme kriterlerine uyan ve gönüllü olan hastalara önce çalışma ile ilgili bilgiler verildi. Daha sonra fizyoterapist tarafından ağrı şiddeti, özürlülük düzeyleri ve postüral kontrol ile ilgili değerlendirmeler yapıldı, veriler veri kayıt formuna kaydedildi.

Çalışmamızda ağrı şiddetini belirlemek için Görsel Analog Skalası (GAS) kullanıldı. Bu skala 0-10 puanlık cetvel aralığında olup yüksek 
değerler gittikçe şiddetlenen ağrıyı ifade etmektedir ${ }^{17}$.

Günlük yaşam için gerekli olan aktiviteleri gerçekleştirme performansını ölçme ve hastaların limitasyonlarını tanımlamada Oswestry Özürlülük İndeksi'nin Türkçe versiyonu kullanıldı. Ağrı şiddeti ile birlikte kişisel bakım, yürüme, kaldırma, ayakta durma, uyku, oturma, cinsel yaşam, sosyal yaşam ve seyahat gibi günlük yaşam aktiviteler sırasındaki fonksiyonel yetersizliği ölçen bu indeks ${ }^{10}$ sorudan oluşmakta, her soruda 6 seçenek bulunmaktaydı ve hastadan durumunu en uygun tanımlayan ifadeyi seçmesi istendi. Her bir soru 0-5 puan arası değerlendirildi. Toplamda 100 puan alınabildiği ankette, hastanın skorunun yüksek olması, özürlülük düzeyinin arttığını göstermektedir ${ }^{18}$.

Hastaların postüral kontrol ile ilgili farklı özellikleri değerlendirmek için spinal ağrılı hastalarda kullanılabilirlik açısından geçerlilik ve güvenilirlik çalışması Sherafat ve arkadaşları tarafindan yapılan Biodex Balance SD (12.1"Display 115 VAC) marka cihaz kullanıld $1^{19}$.

$\mathrm{Bu}$ cihazda yapılan testlerde kararlılık sınırları indeksi (KS) ve duyusal etkileşim denge testi (DEDT) parametreleri değerlendirildi.

Yapılan her iki testte de hastaların ayak pozisyonları ve platform ayarlamaları yapıldı ve cihaza kaydedildi. Testler boyunca hastanın ellerinden destek almaması ve ayak pozisyonunu bozmaması istendi. Her bir test 3 tekrarlı olarak yapıldı.

Kararlılık sınırları indeksi testinde ise hastalar denge platformuna alındıktan sonra sabit sert zemin üzerinde cihazın karışık sırayla ayarladığı 8 farklı noktaya hastanın ayak pozisyonunu bozmadan gitmesi ve her defasında başlangıç pozisyonuna geri dönmesi istendi. Bu test hastanın postüral kontrolünü değerlendirmek için kararlılık sınırları içerisinde durabilme yeteneğini belirlemek amaciyla yapıldı. Bu testin sonunda elde edilen indeks değerlerinin yüksek ve testi tamamlama süresinin az olması dinamik postüral kontrolün daha iyi olduğunu ifade etmektedir.

Duyusal etkileşim denge testinde ise hastalardan sabit sert zemin üzerindeyken önce gözler açı sonra gözler kapalı daha sonra yumuşak zemin üzerindeyken yine sırasıyla gözler açık ve kapalı olarak 30 ar saniye ayak pozisyonunu bozmadan dengede kalması istendi. $\mathrm{Bu}$ test ise postüral kontrolün sağlanmasında hastaların propriyoseptif sistemi ile birlikte vestibular fonksiyonunları hakkında bilgi edinmek için yapıldı. Testin sonunda elde edilen indeks değerlerinin yüksek olması duyusal etkileşim dengesinin daha kötü olduğunu göstermektedir.

\section{İstatistiksel Analiz}

Analizler "SPSS (Statistical Package for the Social Sciences) 25.0 for Windows" programında yapıldı. Bağımlı ve bağımsız değișkenlerin tanımlayıcı istatistikleri frekans değerleriyle gösterilerek aritmetik ortalamalar, minimum ve maksimum değerler belirtildi. Değişkenlerin normal dağılıma uygunluğu Shapiro-Wilk testi kullanılarak incelendi.

Gruplar arası ağrı şiddeti, özürlülük düzeyi ve kararlılık sınırları ve duyusal etkileşim denge özellikleri arasındaki farklar Student-t Testi" ile cinsiyet gibi sayllan değerler Ki-kare Testi ile değerlendirildi.

Anlamllık düzeyi $\mathrm{p}<0.05$ olarak kabul edildi.

Çalıșmanın örneklem büyüklüğü \%95 güven aralığı baz alınarak Open Source Epidemiologic Statistics for Public Health (Open Epi Version 3.1) programı üzerinden evre ve seviyesi MRI ile tanımlanan hastalarda postüral kontrolün 'gözler kapalı duyusal etkileşim dengesi' değişkenine göre hesaplandı ve çalışma verileri sonucunda güç analizi \%80,39 olarak bulundu. 


\section{BULGULAR}

L5-S1 seviyesindeki hastalar bulging ve protrüzyon olarak iki gruba ayrıldığında; hastaların yaş, BKİ (beden kütle indeksi) ve hastalık tanı süresi ortalamaları arasında istatiksel olarak anlamlı fark olmadığı belirlendi ( $p>0.05)$, (Tablo 1).

Tablo I: L5-S1 seviyesinde hastalık evresine göre (bulging ve protrüzyon) yaş, BKİ ve hastalık süresinin karşılaştırılması

\begin{tabular}{|l|c|c|c|}
\hline & Bulging & Protrüzyon & \\
& $\mathrm{n}=22$ & $\mathrm{n}=33$ & $\boldsymbol{p}$ \\
\hline BKI $\pm \mathrm{SS}$ & $\overline{\mathrm{x}} \pm \mathrm{SS}$ & \\
\hline Yaş (yll) & $47.71 \pm 12.50$ & $47.50 \pm 13.60$ & 0.765 \\
\hline $\begin{array}{l}\text { Hastalık } \\
\text { süresi (yll) }\end{array}$ & $4.81 \pm 6.10$ & $5.68 \pm 6.20$ & 0.614 \\
\hline
\end{tabular}

${ }^{*} p<0.05$, student's-t test, BKí: beden kütle indeksi

Bulging ve protrüzyon grubundaki hastaların ağrı şiddeti ve özürlülük indeksi skoru değerlendirme sonuçlarının benzer olduğu ve aradaki farkların istatistiksel olarak anlamlı olmadığ 1 belirlendi ( $p>0.05)$. Fakat denge testlerinden kararlılık sinırlarının bir parametresinde (sol yön testinde) protrüzyon grubu lehine; duyusal etkileşim denge testi parametrelerinden sabit yumuşak zemin (GK) testinde bulging grubu lehine istatiksel olarak anlamlı fark saptandı $(\mathrm{p}<0.05)$, (Tablo 2).
Tablo II: Gruplar arasında ağrı şiddeti, özürlülük, kararlılık sınırları ve duyusal etkileșim denge indekslerinin karşılaștırılması

\begin{tabular}{|c|c|c|c|}
\hline & $\begin{array}{l}\text { Bulging } \\
n=22 \\
\bar{x} \pm S S\end{array}$ & $\begin{array}{l}\text { Protrüzyon } \\
\qquad \begin{array}{c}n=33 \\
\bar{x} \pm S S\end{array}\end{array}$ & $p$ \\
\hline Ağrı (GAS/0-10) & $5.72 \pm 2.70$ & $6.03 \pm 2.60$ & 0.679 \\
\hline $\begin{array}{c}\text { Oswestry özürlülük } \\
\text { indeksi }\end{array}$ & $29.90 \pm 9.50$ & $30.72 \pm 9.00$ & 0.749 \\
\hline $\begin{array}{c}\text { Kararlılık Sınırları } \\
\text { (KS), (indeks) }\end{array}$ & & & \\
\hline Toplam KS & $44.68 \pm 11.30$ & $48.90 \pm 10.50$ & 0.164 \\
\hline Öne & $53.31 \pm 17.00$ & $61.57 \pm 15.00$ & 0.064 \\
\hline Arkaya & $49.54 \pm 19.70$ & $60.15 \pm 18.90$ & 0.050 \\
\hline Sol yöne & $49.63 \pm 15.20$ & $59.69 \pm 16.70$ & $0.028 *$ \\
\hline Sağ yöne & $55.54 \pm 13.80$ & $54.87 \pm 14.20$ & 0.864 \\
\hline Sol ön yöne & $54.40 \pm 17.00$ & $55.72 \pm 11.70$ & 0.735 \\
\hline Sağ ön yöne & $60.54 \pm 13.20$ & $60.54 \pm 15.00$ & 0.999 \\
\hline Sol arka yöne & $50.90 \pm 13.30$ & $53.93 \pm 16.70$ & 0.481 \\
\hline Sağ arka yöne & $43.54 \pm 13.50$ & $50.84 \pm 20.40$ & 0.147 \\
\hline Test süresi (dk) & $0.60 \pm 0.20$ & $0.48 \pm 0.10$ & 0.054 \\
\hline $\begin{array}{c}\text { Duyusal Etkileşim } \\
\text { Denge testi (DEDT) } \\
\text { (indeks) }\end{array}$ & & & \\
\hline GA-SZ & $0.97 \pm 0.60$ & $0.73 \pm 0.40$ & 0.090 \\
\hline GK-SZ & $1.17 \pm 0.50$ & $0.98 \pm 0.50$ & 0.212 \\
\hline GA-YZ & $1.07 \pm 0.70$ & $1.07 \pm 0.60$ & $0.028 *$ \\
\hline GK-YZ & $2.39 \pm 0.80$ & $1.95 \pm 0.60$ & $0.017^{*}$ \\
\hline
\end{tabular}




\section{TARTIŞMA}

Çalışmanın sonuçları, bulgingi ve protrüzyonu olan hastalarda sol ön yön hariç kararlılık sınırlarının benzer olduğunu, fakat protrüzyonu olan hastaların yumuşak zemin duyusal etkileşim dengesinin bulgingi olan hastalara göre daha iyi olduğunu göstermiştir. Başka bir ifadeyle sonuçlarımız, sol taraf kararlılık sinırları ve vestibuler sistemin daha fazla devreye girdiği duyusal etkileşim dengesi açısından bakıldığında postüral kontrolün protrüzyonu olan hastalarda daha iyi olduğunu göstermiştir.

Ağrı lumbal disk hernilerinde sıklıkla karşılaşılan ve hastayı günlük yaşamda en fazla etkileyen faktördür. Lumbal disk hernilerinde ağrı mekanizmalarından biri olan sinir kök basısının yanında, kötü postür, fiziksel kondüsyon yetersizliği, stres, kas kuvvetindeki azalma gibi faktörler, LDH'lı hastalarda dermatomal ağrıya neden olabilmektedir ${ }^{20}$. Literatürde kronik bel ağrlarında, sürecin ilerlemesine bağlı olarak ağrı ve özürlülük şiddetinin arttığını gösteren çalışmalar mevcutsa $\mathrm{da}^{21,22}$, lumbal disk hernili hastalarda yapılan çalışmalar incelendiğinde, dejenerasyon seviyesi arttıkça ağrı ve özürlülüğün arttığını gösteren araştırmaların nadir olduğu görülmektedir ${ }^{23,24}$. Bizim çalışmamız, bu çalışmalardan farklı olarak tek bir seviyede tutulumu olan izole bir hasta grubuna odaklanmıştır. Sonuçlarımız, L5-S1 düzeyinde disk hernisine sahip hastalarda, ağrı ağrı şiddetinin, hastalı evresinden etkilenmediğini göstermiştir. Bunun nedeni, sadece lumbal disk hernisinin ilk evreleri olan bulging ve protrüzyonlu hastaların çalışmaya dahil edilmiş olması ve hastalık süresi açısından iki grup arasında fark olmaması olabilir. $\mathrm{Bu}$ durum, bulging ve protrüzyonu olan hastalardaki ağrı şiddetinin, hastalığın ilerleyen evrelerinde olduğu kadar ciddi olamayabileceği şeklinde yorumlanabilir.
Kronik bel ağrılı hastalarda ağrı şiddetinin postüral kontrole olan etkisini inceleyen bir çalışmada, ağrı şiddeti arttıkça postüral stabilite ve kararlılık sınırlarının olumsuz yönde etkilendiği belirtilmiştir ${ }^{7}$. Benzer bir çalışmada ise farklı ağrı şiddetine sahip olan kronik bel ağrılı hastalarda kararlılık sınırları gözler açık ve kapalı olarak test edilmiştir. Gözler kapalı olarak sağlanan kararlılık sınırlarının ağrı şiddetine göre farklılık gösterdiği sonucuna varılmış ve yüksek ağrı şiddetinin daha az salınıma neden olduğu bildirilmiştir. Bunun nedeni, gözlerin kapanmasının hareket korkusunu artırarak emniyetli bir şekilde durmayı tetiklediği şeklinde yorumlanmıştır. Bir diğer çalışmada ise kronik bel ağrılı hastaların, denge platformu üzerindeki pertürbasyonlara karşı sagital plandaki postüral kontrolü sağlamada, sağlıklı bireylerden daha kötü olduğu bildirilmiștir ${ }^{25}$.

Kronik bel ağrısındaki çalışmalardan farklı olarak, lumbal disk hernisine sahip olan hastalarda yapılan postüral kontrol çalışmalarında ise çalışmaların genellikle cerrahi geçiren hastalarda yapıldığı görülmüştür. Cerrahi öncesi ve cerrahi sonrası postüral salınımların gözler açık ve kapalı olarak değerlendirildiği bir çalışmada özellikle gözler kapalı anteroposterior ve mediolateral yöndeki salınımların cerrahi sonrası erken dönemde, cerrahi öncesinden daha az olduğu bulunmuştur. $\mathrm{Bu}$ sonucun ortaya çlkmasında uygulanan cerrahi sonrasinda meydana gelen postüral stabilite artışı ve proprioseptif kazancın payı olduğu belirtilmiştir ${ }^{26}$. Bir başka çalışmada ise lumbal diskektomi cerrahisi olan hastaların cerrahi sonrasında postüral kontrollerinin tam olarak kazanılamadığı ve postüral salınımlarının gözler kapalı iken, gözlerin açık olduğu duruma göre daha fazla olduğu görülmüştür. Bu durum cerrahi sonrası geç dönemde hastaların postüral kontrollerini sağlamaya yönelik olarak görsel kompansasyon mekanizması geliştirdiği şeklinde 
yorumlanmıştır ${ }^{27}$. $\mathrm{Bu}$ çalışmaların hepsinde hastaların farklı seviyelerde disk hernilerine sahip olduğu belirtilmiştir. Bizim çalışmamızda ise buradaki çalışmalardan farklı olarak tek bir seviyede disk hernisine sahip olan izole bir hasta grubu ele alınmıştır ve bulging ve protrüzyonlu hastalardaki postüral kontrol, hem kararlılık sınırları hem de duyusal etkileşim açısından karşılaştırılmıştır. Bizim sonuçlarımıza göre protrüzyonu olan hastaların sol yönde kararlılık sinırlarının bulgingi olan hastalara göre daha iyi olduğu görülmüştür. Bunun nedeni dominantlığın mediolateral yöndeki salınımlara etki edebildiği olabilir. Bu bulgu, disk herniyasyonunun meydana geldiği anatomik lokalizasyonun, ağırlık aktarma veya postüral salınımların yönündeki bir değişime yol açabileceğini düşündürmektedir. Bunun yanında çalışmamızın bir diğer sonucu olan, protrüzyonu olan hastaların, özellikle yumuşak zemin duyusal etkileşim dengesinin bulgingli hastalara göre daha iyi olması, bu hasta grubunun vestibuler sistemi kullanarak postüral kontrolü sağlamaya yönelik olarak başka kompansasyon mekanizmalarını kullandığını düşündürmektedir.

Bu bulgular ışığında, L5-S1 seviyesinde bulging ve protrüde diski olan hastalarda kararlılık sınırlarının sol yön dişında benzer olduğu, duyusal etkileşim ele alındığında ise protrüde hastalarda vestibuler girdilerin daha az etkilendiği görülmüştür. Bu nedenle aynı seviyede fakat farklı hastalık evrelerine sahip hastalarda bile postüral kontrolün değişebileceği, hastaların tedavisinde hastalık evreleri dikkate alınarak postüral kontrolü geliştirmeye yönelik yaklaşımlarının kullanılması kanısındayız.

Çalışmamızın güçlü yönleri, sıklıkla tutulum gösteren izole bir disk hernisi seviyesine sahip olan hastaların ele alınmış olması, postüral kontrolün objektif ve hem proprioseptif hem de vestibuler sisteme yönelik olarak ayrıntılı değerlendirmiş olması ve literatüre bu açıdan bir bakış açısı sağlayabilecek ilk çalışma olması şeklinde sıralanabilir. Zayıf yönleri ise; vakaların tek bir merkezden alınması, postüral kontrolü etkileyebilecek disk herniyasyonunun meydana geldiği anatomik lokalizasyonun lumbosakral görüntülemelerle ele edilememesi, sadece bulging ve protrüzyonu olan hastaların çalışmaya alınmış olmasıdır. $\mathrm{Bu}$ durum, sonuçların genellenmesi açısından yeterli olmamasına neden olabilir. Gelecek çalışmaların bu eksiklikler göz önüne alınarak daha fazla sayıda hasta ile planlanması, sonuçların geçerliliği ve genellenebilir olması açısından uygun olabilir.

Etik Kurul Kararı: Çalışma için Üniversitenin Girişimsel Olmayan Klinik Araştırmalar Etik Kurulu'ndan 08.06.2017 tarih ve 2017/15-20 karar numarası ile izin alındı. Katılımclara Helsinki Deklerasyonu baz alınarak yazılı aydınlatılmış onam formu okunup imzaları alındı.

Çıkar Çatışması Beyanı: Yazarlar çıkar çatışması olmadığını bildirmişlerdir.

Finansal Destek: Bu çalışma her hangi bir fon tarafından desteklenmemiştir.

Declaration of Conflicting Interests: The authors declare that they have no conflict of interest.

Financial Disclosure: No financial support was received.

\section{KAYNAKLAR}

1. Massion J. Postural control system. Curr Opin Neurobiol. 1994; 4: 877-87.

2. Peterka RJ. Sensorimotor integration in human postural control. J Neurophysiol. 2002; 88: 1097-118.

3. Hodges PW. Pain and motor control: from the laboratory to rehabilitation. J Electromyogr Kinesiol. 2011; 21: 220-8.

4. Hodges PW, Moseley GL. Pain and motor control of the lumbopelvic region: Effect and possible mechanisms. J Electromyogr Kinesiol. 2003; 13: 36170 .

5. Ruhe A, Fejer R, Walker B. Center of pressure excursion as a measure of balance performance in patients with non-specific low back pain compared to healthy controls: a systematic review of the literature. Eur Spine J. 2011; 20: 358-68.

6. Karartı C, Bilgin S, Büyükturan Ö, Büyükturan B, Dadalı Y, Bek N. Lumbopelvik motor kontrol, postüral 
denge ve fiziksel performans arasındaki ilişki. Turk J Physiother Rehabil. 2019; 30: 62-8.

7. Soliman ES, Shousha TM, Alayat MS. The effect of pain severity on postural stability and dynamic limits of stability in chronic low back pain. J Back Musculoskelet Rehabil. 2017; 30: 1023-9.

8. Sipko T, Kuczyński M. The effect of chronic pain intensity on the stability limits in patients with low back pain. J Manipulative Physiol Ther. 2013; 36: 6128.

9. Ruhe A, Fejer R, Walker B. Pain relief is associated with decreasing postural sway in patients with nonspecific low back pain. BMC Musculoskelet Disord. 2012; 13: 39.

10. Taş D, Öztürk Çapur E, Ünlü H, Tüzün Z, Özcebe LH. Quality of life and self-efficacy of adolescents with chronic health conditions. Dicle Med J. 2017; 44: 25765 .

11. Morag E, Hurwitz DE, Andriacchi TP, Hickey M, Andersson GB. Abnormalities in muscle function during gait in relation to the level of lumbar disc herniation. Spine (Phila Pa 1976). 2000; 25: 829-33.

12. Sipko T, Chantsoulis-Supińska $M$, Zmuda $M$, Zwoliński J. Postural balance in the early postoperative period in patients with intervertebral disk disease following surgery. Ortop Traumatol Rehabil. 2008; 10: 226-37.

13. Barrey C, Roussouly P, Perrin G, Le Huec JC. Sagittal balance disorders in severe degenerative spine. Can we identify the compensatory mechanisms? Eur Spine J. 2011; 20: 626-33.

14. Nunes VR, Jacob C Junior, Cardoso IM, Batista JL Junior, Brazolino MA, Maia TC. Spinopelvic balance evaluation of patients with degenerative spondylolisthesis L4L5 and L4L5 herniated disc who underwent surgery. Rev Bras Ortop. 2016; 51: 662-6.

15. Przysada G, Guzik A, Rosak-Matuszewska I, et al. Posture control in patients with herniated nucleus pulposus in cervical and lumbosacral spine subjected to operative treatment. J Back Musculoskelet Rehabil. 2018; 31: 795-802.

16. Li J, Zhang Y, Song S, et al. Dynamical analysis of standing balance control on sloped surfaces in individuals with lumbar disc herniation. Sci Rep. 2020; 10: 1676.
17. Carlsson AM. Assessment of chronic pain. I. Aspects of the reliability and validity of the visual analogue scale. Pain. 1983; 16: 87-101.

18. Yakut E, Düger T, Öksüz C, et al. Validation of the Turkish version of the Oswestry Disability Index for patients with low back pain. Spine (Phila Pa 1976). 2004; 29: 581-5.

19. Sherafat S, Salavati M, Ebrahimi Takamjani I, et al. Intrasession and intersession reliability of postural control in participants with and without nonspecific low back pain using the Biodex Balance System. J Manipulative Physiol Ther. 2013; 36: 111-8.

20. Dower A, Davies MA, Ghahreman A. Pathologic basis of lumbar radicular pain. World Neurosurg. 2019; 128: 114-21.

21. Alamam DM, Moloney N, Leaver A, Alsobayel HI, Mackey MG. Pain intensity and fear avoidance explain disability related to chronic low back pain in a Saudi Arabian population. Spine (Phila Pa 1976). 2019; 44: 889-98.

22. Meints SM, Mawla I, Napadow V, et al. The relationship between catastrophizing and altered pain sensitivity in patients with chronic low-back pain. Pain. 2019; 160: 833-43.

23. Kos N, Gradisnik L, Velnar T. A brief review of the degenerative intervertebral disc disease. Med Arch. 2019; 73: 421-4.

24. McGirt MJ, Ambrossi GL, Datoo G, et al. Recurrent disc herniation and long-term back pain after primary lumbar discectomy: review of outcomes reported for limited versus aggressive disc removal. Neurosurgery. 2009; 64: 338-44.

25. Henry SM, Hitt JR, Jones SL, Bunn JY. Decreased limits of stability in response to postural perturbations in subjects with low back pain. Clin Biomech (Bristol, Avon). 2006; 21: 881-92.

26. Sipko T, Chantsoulis M, Kuczyński M. Postural control in patients with lumbar disc herniation in the early postoperative period. Eur Spine J. 2010; 19: 40914.

27. Bouche K, Stevens V, Cambier D, Caemaert J, Danneels L. Comparison of postural control in unilateral stance between healthy controls and lumbar discectomy patients with and without pain. Eur Spine J. 2006; 15: 423-32. 